\title{
Potentially harmful elements in soil-plant interactions
}

\author{
Jaume Bech
}

Received: 20 February 2014 / Accepted: 21 February 2014/Published online: 14 March 2014

(C) Springer-Verlag Berlin Heidelberg 2014

\section{Background}

The collection of papers presented in this Special Issue is an outcome of the S12.07 Session "Potentially Harmful Elements in Soils" of the EUROSOIL 2012 International Conference held in Bari (Italy) in April 2011, on the part of the European Confederation of Soil Science Societies (ECSSS), the International Union of Soil Sciences (IUSS) and the International Humic Substances Society (IHSS).

Soils are essential components of the environment, the basis of terrestrial ecosystems and a crossroads for biogeochemical cycles at the lithosphere-biosphere interface. The role of the pedosphere is essential for understanding soil-plant interactions, especially through the rhizosphere.

The subject of this Special Issue is of extreme importance, because of the potentially harmful effects of numerous elements on the soil-plant system. The papers in this issue cover important aspects of fundamental and applied research and provide advances in relation to existing knowledge. They deal with essential aspects of potentially harmful substances such as heavy metals, metalloids and polycyclic aromatic hydrocarbons (PAHs) with regard to the interaction of the plant system with soils and sediments.

This Special Issue contains 19 papers written by authors from 11 countries: Canada, Finland, France, India, Israel, Italy, Jordan, Pakistan, Portugal, Russia and Spain. This collection of papers is focused mainly on four topics: soil amendments, mine soils, soil total metal contents and threshold values: the biodegradation of aromatic hydrocarbons and the complexation by aliphatic ligands.

J. Bech $(\bowtie)$

Department of Plant Biology, Soil Science Laboratory, Faculty of

Biology, University of Barcelona, Av. Diagonal 643,

08028 Barcelona, Spain

e-mail: jaumebechborras@gmail.com

\section{Research topics}

\subsection{Soil amendments}

There are seven papers that deal with the first topic: soil amendments.

Shahid et al. (2014a, b) assessed the influence of two phosphorus (P) amendments- $\mathrm{KH}_{2} \mathrm{PO}_{4}$ and $\mathrm{Ca}_{5}\left(\mathrm{PO}_{4}\right)_{3} \mathrm{OH}$ - on metal speciation in rhizosphere soil and soil-plant transfer of metals. This study was performed in field and laboratory experiments with pea, tomato and mustard plants. The authors concluded that the effectiveness of in situ immobilization technique varies with the type and quantity of applied $\mathrm{P}$ amendment, as well as plant and metal type.

The work of Austruy et al. (2014) also deals with the role of $\mathrm{P}$ amendments. The authors investigated metal-phosphates formation in the rhizosphere of pea and tomato plants cultivated in polluted soils with $\mathrm{Pb}$ and $\mathrm{Zn}$ from past industrial activities. Hydroxypatite and $\mathrm{KH}_{2} \mathrm{PO}_{4}$ were used, which caused $\mathrm{Pb}$ and $\mathrm{Zn}$ immobilization in the presence of plants (mainly in the pea rhizosphere), with $\mathrm{KH}_{2} \mathrm{PO}_{4}$ and with more soil-plant contact. They concluded that metal-P complex formation in the contaminated soil depends on the type of $\mathrm{P}$ amendment, the period of soil plant contact, the type of plant species and the excretion of organic acids by the plant roots in the rhizosphere.

Shtangeeva et al. (2014) focused on the problems in the uptake of antimony by wheat (Triticum aestivum $\mathrm{L}$.) seedlings grown in soil enriched with $\mathrm{Sb}$ amendments and the impact of soil amendments on plant growth, as well as the uptake of $\mathrm{Sb}$ from soils and its transfer from roots to upper plant parts. Greenhouse pot experiments were carried out. They concluded that fertilizers could be used to increase phytoextraction of $\mathrm{Sb}$ and its removal from contaminated soils. However, such a soil amendment should be done carefully in order to exclude or at least reduce the negative effects on plants.

Soriano-Disla et al. (2014) estimated the transfer of Cd, Cr, $\mathrm{Cu}, \mathrm{Ni}, \mathrm{Pb}$ and $\mathrm{Zn}$ to barley (Hordeum vulgare $\mathrm{L}$.) grown in 
agricultural soils previously amended with sewage sludge containing different concentrations of heavy metals. Soils slightly restricted the mobility of heavy metals to roots, while plant physiology restricted the transfer of heavy metals from roots to shoots, with further restriction at higher heavy metal loadings. The transfer of $\mathrm{Cd}, \mathrm{Cu}$ and $\mathrm{Zn}$ from soils to shoots was greater than for $\mathrm{Cr}, \mathrm{Ni}$ and $\mathrm{Pb}$. Sandy soils allowed greater soil-plant transfer of $\mathrm{Cr}, \mathrm{Cu}, \mathrm{Pb}$ and $\mathrm{Zn}$. For $\mathrm{Cd}$ and $\mathrm{Ni}$, soils of low $\mathrm{pH}$ and soil organic $\mathrm{C}$ posed the highest risk.

Allué et al. (2014) studied whether tannery sludge could be used for $\mathrm{Cr}$ biofortification of fenugreek (Trigonella foenumgraecum L.). Soils mixed with tannery sludge containing $6.03 \mathrm{~g} \mathrm{Cr}^{3+} \mathrm{kg}^{-1}$ were potted and planted with fenugreek. Plants harvested at the initial flowering stage were analysed for total $\mathrm{Cr}, \mathrm{Fe}, \mathrm{Zn}$ and $\mathrm{Pb}$. Sequential soil extraction was applied to obtain soil $\mathrm{Cr}$ fractions. The authors concluded that tannery sludge-amended soils containing metals within the permitted range of concentrations can increase shoot $\mathrm{Cr}$ in fenugreek. Only sludge with low $\mathrm{Pb}$ concentrations should be used for $\mathrm{Cr}$ biofortification of fenugreek.

Mingorance et al. (2014) investigated the use of stabilized municipal sewage sludge addition to improve acid mine soils for plant growth. A pot trial of improved soils amended with stabilized sewage sludge was carried out with tomato, rye grass and ahipa. Biomass production was improved in tomato and rye grass by sewage sludge addition, whilst ahipa growth was not affected. The authors concluded that amendments with sewage sludge of limed acid mine soils would improve soil amelioration with respect to plant establishment and development.

Rosen and Chen (2014) conducted a bioassay experiment to establish the possible relations between metal concentrations in different soil fractions and metal contents in edible plant parts and to investigate the influence of different compost loads on heavy metal availability to Chinese cabbage plants. The distribution of metals was determined by sequential extraction procedure (modified BCR protocol). The authors found that compost addition increased metal proportions in the reducible hydro/oxides of $\mathrm{Fe}$ and $\mathrm{Mn}$ associated with organic matter fractions, as well as reduced metal phytoavailability. They proposed using the water extractable, exchangeable and adsorbed, and the fraction associated with carbonates and acetic-soluble forms as a three-step sequential extraction procedure for the most phytoavailable fractions of heavy metal.

\subsection{Mine soils}

Eight papers in this Special Issue refer to the second topic: mine soils.

Chaturvedi et al. (2014) studied the growth and physiological response of Tagetes patula L. on iron (Fe) ore tailings. Pot culture experiments were used to investigate the effect of $\mathrm{Fe}$ tailings, both individually, as well as in combination with soil on the growth, pigment production and the accumulation and translocation of heavy metals from the tailings. Bioaccumulation and translocation values were maximum for $\mathrm{Fe}$ and minimum for $\mathrm{Ni}$ and $\mathrm{Cd}$, respectively. The authors concluded that T. patula L. would grow well on the tailings and survive despite an excess of heavy metals. It would also be a potential tool for phytostabilization of Fe ore tailings, and probably a source of income generation from wasteland, owing to its multiple commercial values.

Maleci et al. (2014) examined the effect of heavy metals on the morphology of dandelion (Taraxacum officinale Web.) growing in pots with mine soils to determine the evolution of heavy metal concentrations in leaves and roots over 3 years of cultivation and to highlight possible damage at anatomical and citological level. Plants from contaminated sites show a reduction of leaf thickness proportional to heavy metal concentration and a less organized palisade parenchyma. The parenchyma cells of the roots also displayed mitochondrial alteration. Ultimately, the histological characteristics of leaves and roots exposed a stressed state related to heavy metal content. Moreover, the presence of stress-tolerant mycorrhyzal fungi could reduce metal toxicity.

Abreu et al. (2014) evaluated the biogeochemical impact of the Panasqueira (Portugal) mining activity on soils and Arbutus unedo L. trees, to assess the possible risks for human consumption of the fruits and brandy derived from these and to evaluate the phytostabilization potential of the arbutus tree. Soil, plant and brandy samples were analysed, and the total content (four acid digestion) of $\mathrm{As}, \mathrm{Cd}, \mathrm{Cu}, \mathrm{W}$ and $\mathrm{Zn}$ were determined by inductively coupled plasma atomic emission spectroscopy (ICP). The concentrations were within the normal range for plants, except for $\mathrm{Cd}$ and $\mathrm{Zn}$, which in some samples were above the normal values but without phytotoxic symptoms. According to the EC 466/2001 legislation, arbutus berry consumption does not constitute a health risk for humans, and arbutus trees can be used for phytostabilization in the Panasqueira area.

Santos et al. (2014) studied the effect of interpopulation variation on the accumulation and translocation of potentially harmful elements and nutrients in Cistus ladanifer L. from six mines in the Portuguese Iberian Pyrite Belt. C. ladanifer plants are able to survive in soils with heterogeneous characteristics and polymetallic contamination. Soils from Caveira, Lousal, Neves Corvo and Sao Domingos contained high total concentrations of $\mathrm{As}, \mathrm{Cu}, \mathrm{Pb}$ and $\mathrm{Zn}$, but the soil-available fraction of these elements was low, irrespective of the influence of the mine. The plant species presented interpopulations and intrapopulations variations in the accumulation and translocation of potentially harmful elements and nutrients. However, all studied populations (Caveira, Chança, Lousal, Neves Corvo, Sao Domingos) except Brancanes belong to the same population cluster. 
Amorós et al. (2014) reported the variations in mercury $(\mathrm{Hg})$ and other trace element contents in soil and vine (Vitis vinifera L.) leaves from the Almaden Hg-mining district. Concentrations of $\mathrm{Hg}$ in soils and vine leaves were determined by an atomic absortion Lumex RA-915+ device with a pyrolysis unit (RP-91c). $\mathrm{Hg}$ in soil ranged from 2.376 to $0.04 \mathrm{mg} \mathrm{kg}^{-1}$ in nonpolluted places. Maximum concentrations in leaves were detected in the proximity of the mine and/or the surrounding metallurgical areas.

Pé-Leve Santos et al. (2014) calculated the concentrations of $\mathrm{As}, \mathrm{Cu}, \mathrm{Zn}$ and $\mathrm{W}$ of plants and soils of mining wash sites, in order to compare the uptake of harmful elements from the contaminated soils in the different plants. The quantification was based on the fundamental parameters method for plants and on the WinAxil "compare" mode, using a standard reference material for soils. High concentrations of tungsten were found near the new wash site - and throughout the area - at concentrations many times higher than those recommended by the World Health Organization (WHO).

Rodríguez-Seijo et al. (2014) described the soils that have developed on the tailings from an abandoned $\mathrm{Pb}$ and $\mathrm{Zn}$ mine in Galicia (NW Spain) and determined the soil factors that limit revegetation. These are their low depth, high porosity and stoneniness, low organic matter (OM) and cationexchange capacity (CEC), as well as an imbalance between exchangeable cations. Moreover, the high $\mathrm{Zn}$ and $\mathrm{Pb}$ concentrations hinder revegetation. The restoration procedure recommended by the authors must overcome oxidation processes by adding organic amendments that also contribute towards fixing heavy metals or by implanting spontaneous vegetation such as common broom (Cytisus scoparius) or white birch (Betula celtiberica).

Martínez-López et al. (2014) researched As assimilation by natural vegetation of mining-influenced soils. Two mammals (a sheep and a vole) were selected to study the transfer to the trophic chain. The risk analysis was founded on the contribution of natural plants by ingestion. The As content of soil and plant materials was determined after a microwave digestion by atomic fluorescence spectrometry with flow hydride generation (HG-AES). They concluded that the levels of As in roots were higher than in shoots. The bioconcentration was very low, and the transfer factors, while slightly higher, rarely exceeded unity. When undertaken with the phytoremediation of contaminated sites, the contribution of the As level in plants to the daily diet of animals should be employed as an indicator for the screening of the vegetal species to be used.

\subsection{Soil metal contents and threshold values}

Two papers are concerned with the third topic: soil metal contents and threshold values.

Galán et al. (2014) proposed a robust approach for evaluating the geogenic vs. anthropogenic contribution in polluted soils, based on three steps. Firstly, the trace element contents in potentially polluted soils and their reference and threshold values were compared. Secondly, references and threshold values for the surrounding area were calculated. Thirdly, the results of both types of area were compared.

Acosta et al. (2014) compared soil properties, especially the presence (total and DTPA extractable) and mobility of metals between soils of green areas and bare soil playgrounds in four urban parks in Murcia city (SE Spain). Grasses accumulated less metal than soils, except in roots where $\mathrm{Cr}$ and $\mathrm{Zn}$ were higher than soils by as much as 31 and $17 \%$, respectively. The authors concluded that grasses increased soil OM in green areas and that the soils of urban parks were able to accumulate nutrients for plants and to retain and reduce the mobility and toxicity of metals.

\subsection{Biodegradation of aromatic hydrocarbons and complexation by aliphatic ligands}

Two papers deal with the fourth topic: biodegradation of aromatic hydrocarbons and complexation by aliphatic ligands.

Rocha et al. (2014) investigated the biodegradation of polycyclic aromatic hydrocarbons (PAHs), acenaphthylene (Ace) and benzo[a]anthracene $(\mathrm{BaA})$ by the white rot fungus Pleorotus ostreatus. The biodegradation of Ace and $\mathrm{BaA}$ (alone and in mixtures) by P. ostreatus was studied in a sandy soil. The results indicate that the fungal degradation of Ace and BaA was not influenced by the presence of each other's PAH in sandy soils. The bioremediation of soils contaminated with Ace and $\mathrm{BaA}$ using P. ostreatus is an interesting way of eliminating these PAHs from the polluted soils.

Shahid et al. (2014a, b) evaluated the effect of organic ligands such as EDTA and citric acid on Pb-induced oxidative stress to Vicia faba L. roots. They concluded that EDTA could inhibit $\mathrm{Pb}$-induced toxicity to $V . f a b a \mathrm{~L}$. seedlings by forming stable PbEDTA complexes due to its high binding strength for $\mathrm{Pb}$. However, citric acid had no effect, due to weak complexation with $\mathrm{Pb}$.

\section{Conclusions}

All the papers described above cover important aspects of fundamental and applied research and provide advances in relation to existing knowledge.

Acknowledgments I would firstly like to thank the co-guest editors Prof. Dr. Maria Manuela Abreu (Instituto Superior de Agronomia, Universidade Técnica de Lisboa, TU Lisbon, Portugal), Prof. Dr. Claudio Bini (Department of Environmental Sciences, University of Venice, Venice, Italy), Prof. Dr. Jadwiga Gzyl (Institute for Ecology of Industrial Areas, Katowice, Poland), Prof. Dr. Carmen Perez-Sirvent (Faculty of Chemistry, University of Murcia, Murcia, Spain), Prof. Dr. Charlotte Poschenrieder (Plant Physiology Lab., Facultat Biociencies. Universitat 
Autonoma de Barcelona, Bellaterra, Spain) for their essential and excellent collaboration. Also, I would like to thank the authors for their contributions and for their patience with the review process, as well as the reviewers for their objective observations. Their efforts have improved the quality of this Special Issue. The technical assistance of A. Young is greatly appreciated. I am also extremely grateful to Prof Dr. Philip N. Owens and Prof. Dr. Zhihong Xu, Editors-in-Chief of the Journal of Soils and Sediments and to Moira Ledger, Editorial Manager, without whose knowledge and experience this Special Issue could not have been published.

\section{References}

Abreu MM, Godinho B, Magalhães MCF (2014) Risk assessment of Arbutus unedo L. fruits from plants growing in contaminated soils in the Panasqueira mine area, Portugal. J Soils Sediments. doi:10.1007/ s11368-013-0835-7, this issue

Acosta JA, Faz A, Martínez-Martínez S, Arocena JM (2014) Grassinduced changes in properties of soils in urban green areas focusing on the mobility of metals. J Soils Sediments. doi:10.1007/s11368013-0830-z, this issue

Allué J, Garcés AM, Bech J, Barceló J, Poschenrieder J (2014) Fractionation of chromium in tannery sludge-amended soil and its availability to fenugreek plants. J Soils Sediments. doi:10.1007/ s11368-013-0776-1

Amorós J-A, Esbrí JM, García-Navarro F-J, Pérez-de-los-Reyes C, Bravo S, Villaseñor B, Higueras P (2014) Variations in mercury and other trace elements contents in soil and in vine leaves from the Almadén Hg-mining district. J Soils Sediments. doi:10.1007/s11368-0130783-2, this issue

Austruy A, Shahid M, Xiong T, Castrec M, Payre V, Niazi NK, Sabir M, Dumat C (2014) Mechanisms of metal-phosphates formation in the rhizosphere soils of pea and tomato: environmental and sanitary consequences. J Soils Sediments. doi:10.1007/s11368-014-0862-z, this issue

Chaturvedi N, Ahmed MJ, Dhal NK (2014) Effects of iron ore tailings on growth and physiological activities of Tagetes patula L. J Soils Sediments. doi:10.1007/s11368-013-0777-0, this issue

Galán E, González I, Romero A, Aparicio P (2014) A methodological approach to estimate the geogenic contribution in soils potentially polluted by trace elements. Application to a case study. J Soils Sediments. doi:10.1007/s11368-013-0784-1, this issue

Maleci L, Buffa G, Wahsha M, Bini C (2014) Morphological changes induced by heavy metals in dandelion (Taraxacum officinale Web.) growing in mine soils. J Soils Sediments. doi:10.1007/s11368-0130823-y
Martínez-López S, Martínez-Sánchez MJ, Pérez-Sirvent C, Bech J, del Carmen Gómez Martínez M, García-Fernandez AJ (2014) Screening of wild plants for use in the phytoremediation of mining-influenced soils containing arsenic in semi-arid environments. J Soils Sediments. doi:10.1007/s11368-013-0836-6, this issue

Mingorance MD, Rossini Oliva S, Valdés B, Pina Gata FJ, Leidi EO, Guzmán I, Peña A (2014) Stabilized municipal sewage sludge addition to improve properties of an acid mine soil for plant growth. J Soils Sediments. doi:10.1007/s11368-013-0743-x

Pé-Leve Santos SC, Cruz ME, Barroso AME, Fonseca CPS, Guerra M, Carvalho ML, Santos JP (2014) Elemental characterization of plants and soils in Panasqueira tungsten mining region. J Soils Sediments. doi:10.1007/s11368-013-0788-x, this issue

Rocha I, Pinto E, Ferreira IMPLVO, da Silva MV, Oliveira RS (2014) Influence of mixtures of acenaphthylene and benzo[a] anthracene on their degradation by Pleurotus ostreatus in sandy soil. J Soils Sediments. doi:10.1007/s11368-013-0804-1, this issue

Rodríguez-Seijo A, Arenas-Lago D, Lago-Vila M, Vega FA, Andrade Couce L (2014) Limitations for revegetation in lead/zinc minesoils (NW Spain). J Soils Sediments. doi:10.1007/s11368-013-0826-8, this issue

Rosen V, Chen Y (2014) The influence of compost addition on heavy metal distribution between operationally defined geochemical fractions and on metal accumulation in plant. J Soils Sediments. doi:10. 1007/s11368-013-0819-7, this issue

Santos ES, Abreu MM, Batista MJ, Magalhães MCF, Fernandes E (2014) Inter-population variation of the accumulation and translocation of potentially harmful chemical elements in Cistus ladanifer L. from Brancanes, Caveira, Chança, Lousal, Neves Corvo and São Domingos mines in the Portuguese Iberian Pyrite Belt. J Soils Sediments. doi:10.1007/s11368-014-0852-1, this issue

Shahid M, Dumat C, Pourrut B, Silvestre J, Laplanche C, Pinelli E (2014a) Influence of EDTA and citric acid on lead-induced oxidative stress to Vicia faba roots. J Soils Sediments. doi:10.1007/ s11368-013-0724-0, this issue

Shahid M, Xiong T, Masood N, Leveque T, Quenea K, Austruy A, Foucault Y, Dumat C (2014b) Influence of plant species and phosphorus amendments on metal speciation and bioavailability in smelter impacted soils: a case study of food-chain contamination. J Soils Sediments. doi:10.1007/s11368-013-0745-8, this issue

Shtangeeva I, Niemelä M, Perämäki P (2014) Effects of soil amendments on antimony uptake by wheat. J Soils Sediments. doi:10.1007/ s11368-013-0761-8, this issue

Soriano-Disla JM, Gómez I, Navarro-Pedreño J, Jordán MM (2014) The transfer of heavy metals to barley plants from soils amended with sewage sludge with different heavy metal burdens. J Soils Sediments. doi:10.1007/s11368-013-0773-4, this issue 